Corrigendum

\title{
Corrigendum to "Distribution of Trace Elements, Sr-C Isotopes, and Sedimentary Characteristics as Paleoenvironmental Indicator of the Late Permian Linxi Formation in the Linxi Area, Eastern Inner Mongolia"
}

\author{
Linlin Wang $\left(\mathbb{D},{ }^{1}\right.$ Yongsheng Zhang $\left(\mathbb{D},{ }^{2}\right.$ Enyuan Xing, ${ }^{2}$ Yuan Peng, ${ }^{2}$ and Dongdong Yu ${ }^{2}$ \\ ${ }^{1}$ Petroleum Exploration \& Production Research Institute, SINOPEC, Beijing 100083, China \\ ${ }^{2}$ Institute of Mineral Resources, CAGS, Beijing 100037, China \\ Correspondence should be addressed to Yongsheng Zhang; zys0601@126.com \\ Received 2 September 2020; Accepted 2 September 2020; Published 8 October 2020 \\ Copyright (c) 2020 Linlin Wang et al. This is an open access article distributed under the Creative Commons Attribution License, \\ which permits unrestricted use, distribution, and reproduction in any medium, provided the original work is properly cited.
}

In the article titled "Distribution of Trace Elements, Sr-C Isotopes, and Sedimentary Characteristics as Paleoenvironmental Indicator of the Late Permian Linxi Formation in the Linxi Area, Eastern Inner Mongolia" [1], Dr. Yongsheng Zhang should be listed as the corresponding author as he made important contributions to this article.

Additionally, the acknowledgements section should be corrected as follows:

"This research was partially supported by the National Natural Science Foundation of China (no. 41572098) and the National Key R\&D Program of China under grant 2017YFC0603103."

\section{References}

[1] L. Wang, Y. Zhang, E. Xing, Y. Peng, and D. Yu, "Distribution of trace elements, Sr-C isotopes, and sedimentary characteristics as paleoenvironmental indicator of the late Permian Linxi formation in the Linxi area, eastern Inner Mongolia," Journal of Chemistry, vol. 2020, Article ID 7027631, 17 pages, 2020. 